\title{
Computer and internet use by first year clinical and nursing students in a Nigerian teaching hospital Grace Ada Ajuwon*
}

\author{
Address: E. Latunde Odeku Medical Library, College of Medicine, University of Ibadan, Nigeria \\ Email: Grace Ada Ajuwon* - agajuwon@yahoo.com \\ * Corresponding author
}

Published: 18 September 2003

BMC Medical Informatics and Decision Making 2003, 3:10
Received: 05 April 2003

Accepted: 18 September 2003

This article is available from: http://www.biomedcentral.com/1472-6947/3/10

(C) 2003 Ajuwon; licensee BioMed Central Ltd. This is an Open Access article: verbatim copying and redistribution of this article are permitted in all media for any purpose, provided this notice is preserved along with the article's original URL.

\begin{abstract}
Background: The internet is an important source of up-to-date medical information. Although several studies in different countries have explored the extent to which health science students use the computer and the internet, few researches are available on this subject in Nigeria. The aim of this study was to assess the uptake of computer and internet by health science students studying in the country.
\end{abstract}

Methods: One hundred and eighty three first year medical and nursing students of the University College Hospital, Ibadan, Nigeria, completed a-25 item questionnaire during routine Library Orientation Program in the medical library. The EPI-Info software was used for data analysis.

Results: The mean ages for medical students and the student nurses were 22 and 24.6 years respectively. Overall, $42.6 \%$ of the entire sample could use the computer, $57.4 \%$ could not. While more than half $(58 \%)$ of the medical students are computer literate, majority $(75.9 \%)$ of the student nurses are not. Slightly more than two thirds $(60.7 \%)$ of the entire students had ever used the internet, $33.9 \%$ had not. E-mail was the most popular of internet services used by the students (76.4\%) and the cyber café was the common place where students had accessed these services. The students' mean scores on a I5-point perceived self-efficacy scale for internet-related tasks was 3.8 for medical and 0.7 for nursing students $(p=0.00)$. Students who are computer literate had superior mean scores $(4.8)$ than those without $(0.6)(p=0.000)$.

Conclusion: First year clinical and nursing students in Ibadan Nigeria have not fully utilised the opportunity that the use of computer and internet offer for medical education. Improved efforts such as inclusion of computer education in medical and nursing curricular and establishment of computer laboratories are required to increase the student's access to computers and internet.

\section{Background}

Advances in telecommunication technology in the last two decades have led to the development of computer networks that allow access to vast amount of information and services [1]. Of the many computer networks that have been developed, the most prominent and widespread is the Internet, a global network of networks that enables computers of all kinds to directly and transparently communicate throughout the world. This 'global network of networks' has been described as the 'Information Super-highway' or 'Infobahn' because it constitutes a shared global resource of knowledge, and means of collaboration and co-operation in diverse communities [2]. It is an open and unregulated community of people who 
communicate freely across an international electronic computer network [3]. It is simply the linking together of individual computers in a network [4]. The Internet was originally conceived by the United States of America's military in the sixties, as a means of ensuring a workable communication system in the event of a strike by enemy missiles or forces [5]. It has grown over the years to include academic and government computers as well as any one who owns a computer, a modem and an account with an Internet Service Provider. Although there is no precise statistics, it is estimated that there are at lest 100,000 networks, attached to more than 5 million computers located in over 100 countries, connected to the Internet. While access to the Internet was originally restricted to government departments, and organizations such as universities, in the 1990s it became available to those with access to a computer network, in both the developed and developing countries [6].

As in many other fields, the Internet is also present in medical domain. The development of the Internet, as a vehicle for World-wide communication, and the emergence of the World Wide Web, has made instantaneous access to much of the entire body of medical information an exciting one [7]. It is now one of the most important sources of information for students in institutions of higher learning throughout the world. It has also become a popular medium for delivering educational materials. The Internet has been used for medical education in diverse ways including teaching of organs, diagnosis of diseases, and conduct of medical examinations [8-13]. It is also being used as an important source of information for medical research [11]. Medical and nursing students who have participated in online education have stated that this mode of education has several advantages over traditional method of instruction. These advantages include the convenience of taking a course at a time that fitted students schedule and at a place that they did not have to commute to attend [14]. Online learning also assists students with the practical application of theoretical knowledge of some aspects of medicine such as cardiology [15].

Despite these advantages, online learning has certain limitations. For example, some students have complained of insufficient time and limited computer access [14]. Others claimed that this mode of instruction lack interactivity among students and between the students and the instructor that would be achieved in the ideal classroom setting [16]. Internet teleconferencing, however, appears to offer for real-time interactive classroom meeting on the Internet [16]. In addition, visual learners were more apt than audio learners to gain from online learning [16]. On-line learning has also been found to be consumer focused and many perceive online advertisement to be distracting [15].
Finally, the information available on the Internet can be overwhelming for students who lack the skills for verifying the quality of information available on-line [17].

While several researches have explored the extent to which health science students use Internet services in many countries, [8], [9] few of such studies are currently available in Nigeria. The aim of this study is to assess the level of computer and Internet use amongst first year Clinical students and students Nurses studying in Nigeria.

\section{Methods \\ The setting}

The University College Hospital (UCH), Ibadan, was established in 1957 and as such it is the oldest federal institution for tertiary health care, teaching and research in Nigeria The hospital has 45 medical specialty and subspecialties/disciplines and runs 75 consultative clinics weekly with 805 beds for admission. Apart from providing care, $\mathrm{UCH}$ is also a major training institution for diverse categories of health workers in the country. Through the University of Ibadan, UCH had trained over 5, 000 physicians and dentists and has produced approximately an equal number of scholarly publications of health-related researches. The hospital itself has trained more than 6, 000 nurses and midwives since inception and several hundred other health professionals including medical laboratory scientists, teachers of community health, environmental health, medical records and radiography. To date over 12 million patients have received care in the hospital [18].

The study population consists of medical students who are in their first year of clinical study and first year nursing students enrolled in UCH during 2001/2002 academic Session.

\section{Recruitment procedures}

The students were recruited into the study during the routine library orientation program organized by the author for all fresh student users of the Latunde Odeku Medical Library (LOML), which serves both students and faculty of the University of Ibadan and the UCH. The data were collected as part of efforts to assess the needs of students on use of computer and Internet, which is a component of the services provided at LOML. A questionnaire that consisted of 25 items was used for data collection. It elicited demographic profile, use of computer and internetrelated resources. The questionnaire also assessed the students' perceived self-efficacy to perform five-internetrelated tasks, including ability to download messages from the Internet, and search the Internet for classification of diseases. The questionnaire was pre-tested among a group of 20 students' library users, and was revised to enhance its clarity and comprehension. Verbal informed 
Table I: Demographic profiles of the students

\begin{tabular}{|c|c|c|c|}
\hline Item & Student Nurses $(\mathrm{N}=83)$ & Medical students $(\mathrm{N}=100)$ & Total $N=(183)$ \\
\hline \multicolumn{4}{|l|}{ I. Age } \\
\hline $17-19$ & $19(22.9)$ & $2(2.0)$ & $21(11.5)$ \\
\hline $20-22$ & $28(33.7)$ & $64(64)$ & $92(50.3)$ \\
\hline $23-25$ & $8(9.6)$ & $30(30)$ & $38(20.8)$ \\
\hline $26-30$ & $8(9.6)$ & $4(4)$ & $12(6.6)$ \\
\hline $31-35$ & $14(16.9)$ & 0 & $14(7.6)$ \\
\hline 36 and above & $6(7.2)$ & 0 & $6(3.3)$ \\
\hline Age range $17-45$ & Mean $=25 ;(+66.782)$ & Mean $=22 ;\left(+\_1.457\right)$ & \\
\hline \multicolumn{4}{|l|}{ Sex } \\
\hline Males & $21(25.3)$ & $62(62)$ & $83(45.4)$ \\
\hline Females & $62(74.7)$ & $38(38)$ & $100(54.6)$ \\
\hline
\end{tabular}

$* \%$ are in brackets

consent was obtained from the students by disclosing that the data collected was for research purpose, that the questionnaire was anonymous, and that their participation in the study was voluntary.

All of the 100 clinical students and 83 student nurses who showed up for the orientation program agreed to participate in the study (response rate 100\%). The questionnaires were self-administered and collected shortly before the orientation program commenced. The data were entered into the computer and analysis was done using the EPI-Info software developed by the Center for Disease Prevention and Control, Atlanta, Georgia, USA. The analysis is descriptive. The data on perceived level of confidence was summarized by assigning 3 points to those who are "very confident", 2 to those that have "little confident" and 1 to those who are "not confident at all". This was used to develop a 15 - perceived self-efficacy score.

\section{Results}

\section{Demographic profile of students}

The demographic profile of the students is described in Table 1 . There are more female nurses $(74.7 \%)$ than males $(25.3 \%)$; by contrast the medical students have more males $(62 \%)$ than females $(38 \%)$. The ages of the students ranged from 17-45 years; the mean age for student nurses is 24.6 years while that of medical students was 22 years.

\section{Use of the computer}

The students' ability and pattern of use of the computer is presented in Table 2 . Overall, only $42.6 \%$ of the sample could use the computer, $57.4 \%$ could not. More than half $(58 \%)$ of the medical students are computer literate, $75.9 \%$ of the student nurses are not. Majority $(69.8 \%)$ of the student nurses who cannot use the computer claimed that they do not have access to a computer system. The $42 \%$ of the medical students who cannot do so said they do not have the time to learn how to use it. Among computer literate students, Microsoft Word was the most popular (66.2\%) software ever used, followed by Word Perfect $(25.6 \%)$.

\section{Use of the internet}

The students' use of Internet services and resources is shown in Table 3. Overall, $60.7 \%$ of the entire sample had used the Internet, $33.9 \%$ had not. However, more medical students (63\%) than student nurses (12.5\%) had used the Internet. Sixty five percent of the medical students claimed that they regularly obtained health-related information from the Internet as compared to $28.9 \%$ of the student nurses. The Email was the most popular of Internet services used by the students (76.4\%), comprising of $81.3 \%$ medical and $73.4 \%$ student nurses. Forty-one percent of the 111 students who had ever used the Internet claimed that someone assisted them, 55.9\% completed the task on their own. The Cyber café is the common place $(87.3 \%)$ where students had accessed Internet services. Concerning search engines used, Yahoo is the most popular $(89.1 \%)$, which was used by $93.8 \%$ student nurses and medical students (87.3\%). Majority of the students, (67.5\% student nurses and 72\% medical students) have not searched a database before.

Perceived self-efficacy in performing internet-related tasks The students were requested to determine the extent to which they perceived themselves confident in performing five Internet-related tasks. Their perceived ability to perform these tasks is shown in Table 4 . A total of $86.2 \%$ of medical students were "very confident" to download materials from the Internet compared to $13.8 \%$ of student nurses. While $89.5 \%$ of the medical students were "very 
Table 2: Pattern of use of the computer by nursing and medical students

\begin{tabular}{|c|c|c|c|}
\hline Item & Student Nurses $(\mathrm{N}=83)$ & Medical students $(\mathrm{N}=100)$ & Total $(\mathrm{N}=183)$ \\
\hline \multicolumn{4}{|l|}{ I. Computer literacy } \\
\hline Yes & $20(24.1)$ & $58(58)$ & $78(42.6)$ \\
\hline No & $63(75.9)$ & $42(42)$ & $105(57.4)$ \\
\hline \multicolumn{4}{|l|}{$\begin{array}{l}\text { 2. Reasons for Computer- } \\
\text { illiteracy. }\end{array}$} \\
\hline a. I don't have the time & $17(27.0)$ & $21(50.0)$ & $38(36.2)$ \\
\hline \multirow{2}{*}{$\begin{array}{l}\text { b. I have no access to a } \\
\text { computer. }\end{array}$} & $44(69.8)$ & $20(47.6)$ & $64(61.0)$ \\
\hline & & & $2(1.9)$ \\
\hline c. I'm not interested & I (I.6) & & $I(0.9)$ \\
\hline d. No response & $\mathrm{I}(1.6)$ & I (2.4) & \\
\hline \multicolumn{4}{|l|}{ 3. Types of programs used } \\
\hline 1. Word perfect & $4(20)$ & $15(26.0)$ & $19(25.6)$ \\
\hline 2. Microsoft word & II (55) & $38(65.5)$ & $49(66.2)$ \\
\hline 3. MS DOS & I (5) & $2(3.4)$ & $3(4.1)$ \\
\hline 4. Dbase & I (5) & $\mathrm{I}(\mathrm{I} .7)$ & $2(2.7)$ \\
\hline 5. Corel Draw & I (5) & $2(3.4)$ & $\mathrm{I}(1.4)$ \\
\hline 6. Others & $2(10)$ & $\mathrm{I}(\mathrm{I} .7)$ & \\
\hline \multicolumn{4}{|l|}{$\begin{array}{l}\text { 4. Information sources use by } \\
\text { Students. }\end{array}$} \\
\hline a. Textbooks & $14(16.9)$ & $15(15.0)$ & $29(15.9)$ \\
\hline b. Journals & $10(12.0)$ & $7(7.0)$ & $17(8.3)$ \\
\hline c. The Internet & $24(28.9)$ & $65(65.0)$ & $89(48.6)$ \\
\hline d. MEDLINE on CD_ROM & $14(16.9)$ & I (I.0) & $15(8.2)$ \\
\hline e. No response & $21(25.3)$ & $12(12.0)$ & $33(18.0)$ \\
\hline
\end{tabular}

confident" in accessing information on Compact Disc Read Only Memory (CD-ROM), only $15.2 \%$ of the student nurses are very confident in performing this task. Regarding ability to download an article from an online journal, $21.5 \%$ of medical students and $4.1 \%$ of nursing students were "very confident" to perform this task. Overall, the mean for the two groups was 3.8 and 0.7 for medical and nursing students respectively $(p=0.00)$. When the level of confidence scores was compared with gender it was found that overall males significantly had superior mean scores (3.4) than females (1.6) $(\mathrm{p}=0.004)$. Students who are computer literate also had superior mean scores than those who are not ( 4.8 vs. 0.6$)(\mathrm{p}=0.000)$. Those who had ever used the Internet also had higher mean scores than those who had not (3.6 vs. 0.5$)(\mathrm{p}=$ $0.000)$.

\section{Discussion}

There have been rapid advances in communication and information technology, in the past few years and the pervasion of the World Wide Web into everyday life has important implications for medical education [17]. The use of the computer and the Internet technology by health science students will result in more effective medical education, including teaching, medical examination, and diagnosis of disease [9]. However, these gains will only occur when students have increased access to this technology. In this study, only $43 \%$ of the sample could use the computer. This figure is lower than the $84 \%$ of undergraduate students in Glasgow, United Kingdom (UK) [8], 94\% of medical students from Jeddah, Saudi Arabia [9] and 95\% undergraduate dental students in Oulu, Finland [10]. Similar studies have found higher proportion of students had used the computer: $61 \%$ medical students from Malaysia [19], 80\% final year medical students from Lagos, Nigeria [11]. The relatively lower proportion of those who could use the computer in this study may be a reflection of a limited access to computers among first year health sciences students in Nigeria. The relatively high cost of this product within the country is one of the primary reasons for this situation. Increased funding to Universities by government and Non-Governmental Agencies (NGA) is likely to solve this problem. This would enable Nigerian universities to set-up computer laboratories in various faculties where students can 
Table 3: Patterns of use of Internet services by students

\begin{tabular}{|c|c|c|c|}
\hline Item & Student Nurses $(\mathrm{N}=83) \mathrm{No} \%$ & Medical students ( $\mathrm{N}=100 \mathrm{No} \%$ & Total $(\mathrm{N}=183)$ \\
\hline \multicolumn{4}{|l|}{ Ever used the Internet? } \\
\hline Yes & $32(38.6)$ & $79(79)$ & III (60.7) \\
\hline No & $4 I(49.4)$ & $2 I(2 I)$ & $62(33.9)$ \\
\hline No response & $10(12.0)$ & 0 & $10(5.5)$ \\
\hline \multicolumn{4}{|c|}{ Frequency of Internet use. } \\
\hline \multicolumn{4}{|c|}{ I. Most frequently } \\
\hline 2. Regularly & $4(12.5)$ & $5(6.3)$ & $9(8.1)$ \\
\hline 3. Occasionally & $7(21.9)$ & $29(36.7)$ & $36(32.4)$ \\
\hline \multirow[t]{2}{*}{ 4. Rarely } & $15(46.9)$ & $27(34.2)$ & $42(37.8)$ \\
\hline & $6(18.8)$ & $18(22.8)$ & $24(21.6)$ \\
\hline \multicolumn{4}{|c|}{$\begin{array}{l}\text { 2. Internet services used by } \\
\text { students }\end{array}$} \\
\hline a. E-mail & $26(81.3)$ & $58(73.4)$ & $84(75.7)$ \\
\hline b. Web browsing & $2(12.5)$ & $21(26.6)$ & $25(22.5)$ \\
\hline c. Games & I (3.1) & 0 & I (0.9) \\
\hline d. Others (movies) & I (3.I) & 0 & $\mathrm{I}(0.9)$ \\
\hline \multicolumn{4}{|l|}{ 3. Mode of Internet use } \\
\hline a. Assisted & $18(59.4)$ & $30(30.0)$ & $49(44.1)$ \\
\hline b. Not Assisted & $13(40.6)$ & $49(62.0)$ & $62(55.8)$ \\
\hline \multicolumn{4}{|c|}{$\begin{array}{l}\text { 4. Where Internet service was } \\
\text { Used. }\end{array}$} \\
\hline a. Cyber café & $28(87.5)$ & $69(87.3)$ & $97(87.4)$ \\
\hline b. Home & 0 & $9(11.4)$ & $9(8.1)$ \\
\hline c. Library & $\mathrm{I}(3.1)$ & 0 & I (0.9) \\
\hline d. A friend's house & $3(9.4)$ & $\mathrm{I}(\mathrm{I} .3)$ & $4(3.6)$ \\
\hline \multicolumn{4}{|l|}{ 5. Search engines used } \\
\hline a. Yahoo & $30(93.8)$ & $69(87.3)$ & $99(89.2)$ \\
\hline b. Google & I (3.I) & $9(11.4)$ & $10(9.0)$ \\
\hline c. Alta Vista & I (3.I) & 0 & I (0.9) \\
\hline d. Ask Jeeves & & $\mathrm{I}(\mathrm{I} .3)$ & I (0.9) \\
\hline
\end{tabular}

have full access to Internet services as it is done in other countries including America [20].

Although $43 \%$ of the entire sample in this study was computer literate, a larger majority $(61 \%)$ had used the Internet. This figure is comparable to the findings from similar studies. In Malaysia, 67\% of Medical students surveyed reported adequate skills in browsing the Internet $78 \%$ in using the e-mail [19]. Similarly, in Lagos, Nigeria, the Internet and e-mail were used by $58 \%$ of medical students [11] and 53\% dental students in the UK [21]. The difference between level of computer literacy and use of Internet services found in this study could be explained by the fact that the majority of those who used the Internet were assisted in doing so.
More medical students, than student nurses had used both the computer and the Internet. In addition, more medical students than student nurses regularly obtained health-related information from the Internet. Similar findings have been reported in Glasgow where more medical students than nursing students had used the computer and the Internet [8]. Other investigators have reported similar findings [8], [9]. In this survey, medical students may have had greater appreciation of the relevance of the Internet to their education since they have spent some part of their undergraduate years on the main campus of the University of Ibadan. Thus, many of them may have come to see the Internet as a valued source of information for their training. On the other hand, majority of the student nurses may not have had the opportunity to use the Internet since they have just recently left secondary school 
Table 4: Perceived confidence in performing Internet related tasks by the students

\begin{tabular}{|c|c|c|c|c|c|c|}
\hline \multirow[b]{2}{*}{ Tasks } & \multicolumn{3}{|c|}{ Student Nurses $(\mathrm{N}=83)$} & \multicolumn{3}{|c|}{ Medical students $(\mathrm{N}=100)$} \\
\hline & Not Confident & Little confident & Very confident & Not confident & Little confident & Very Confident \\
\hline $\begin{array}{l}\text { Download free medical books } \\
\text { from the internet }\end{array}$ & $71.2 \%$ & $21.2 \%$ & $7.7 \%$ & $31.7 \%$ & $37.8 \%$ & $30.5 \%$ \\
\hline $\begin{array}{l}\text { Search the Internet for } \\
\text { classification of diseases. }\end{array}$ & $67.3 \%$ & $23.1 \%$ & $9.6 \%$ & $32.9 \%$ & $28.0 \%$ & $39.0 \%$ \\
\hline $\begin{array}{l}\text { Search the Internet for a list of } \\
\text { health sciences libraries in Africa }\end{array}$ & $69.8 \%$ & $24.5 \%$ & $5.7 \%$ & $31.7 \%$ & $37.8 \%$ & $30.5 \%$ \\
\hline Access information on CD-ROM & $74.0 \%$ & $16.0 \%$ & $10.0 \%$ & $31.6 \%$ & $31.6 \%$ & $36.8 \%$ \\
\hline $\begin{array}{l}\text { Retrieve and download full- } \\
\text { textarticle from an online journal } \\
\text { (BMJ) }\end{array}$ & $79.6 \%$ & $16.3 \%$ & $4.1 \%$ & $44.3 \%$ & $34.2 \%$ & $21.5 \%$ \\
\hline
\end{tabular}

for the school of nursing. It is also possible that the importance of the Internet has not been emphasized in their previous and present education.

E-mail was the most popular of the Internet services used by the students. This is comparable to previous studies where e-mail use was high (78\%) among medical students in Malaysia [20]. E-mail is the fastest and cheapest means of electronic communication in the world today. Access to this service has increased in recent years in Nigeria due to the proliferation of cyber cafes in many towns and cities, which in turn has reduced the cost of this service. However, access to e-mail services is not readily available to many people living in rural areas of the country.

\section{Program implications}

The data from this survey has provided baseline information for making appropriate recommendations. Four interventions are recommended to address the problem of low utilization of the computer and Internet by health science students in Ibadan, Nigeria. First, government, NGA and interested philanthropists need to provide funding assistance to enable universities in Nigeria purchase computers linked with Internet facilities to improve students' access to the resources available on-line. Secondly, providing direct loan to students is another potentially feasible intervention that would enable them purchase personal computers. In this regard, the buddy system can be encouraged in which students who own computers could in turn assist others to learn how to use the computer and the Internet. Thirdly, the faculty has important role to play in improving students' access to use of computer and Internet services. For example, the faculty may encourage students to use Internet services by creating web pages that students can visit as part of their learning. Finally, students' interest to use the computer would be kindled if an introductory course on computer use were included into existing medical and nursing curricular in the universities and teaching hospitals in the country.

The findings of this study particularly the system of learning to use the computer and Internet from friends and colleagues needs further investigation.

\section{Conclusions}

The use of the computer and Internet is rapidly becoming a key component of medical education in many parts of the world. Although the Internet is an important source of medical information, first year medical and nursing students in Ibadan, Nigeria, have not fully utilized these facilities. Increased funding, introduction of computer education into existing medical and nursing curricular would enhance students' ability to acquire, appraise, and use information from the Internet to solve health problems quickly and efficiently during training and practice.

\section{List of abbreviations}

- ELOML (E. Latunde Odeku Medical Library)

- UCH (University College Hospital)

- LOP (Library Orientation Program)

- Non-Governmental Agencies

\section{Competing interests}

none declared.

\section{Authors' contributions}

GA is the sole contributor to this manuscript.

\section{Acknowledgements}

I thank all the students who participated in this study. 


\section{References}

I. Glowniak JV: Medical resources on the internet. Ann Intern Med 1995, I 23(3):|23-|3|.

2. The Internet Society: What is the Internet? 2002 [http:// www.isoc.org/internet/]

3. Coiera E: Medical informatics. $B M]$ 1995, 3 | 0: | 38 I- | 386.

4. Mckenzie BC: Medicine and the internet: introducing on-line resources and terminology. New-York, Oxford University Press 1997:97.

5. December J and Randall N: The world wide web unleashed. Indianapolis, Sams Publishers 1994:6.

6. Millman A, Lee $\mathrm{N}$ and Kealy K: ABC of the Medical Computing Internet. BM] 1995, 3 I I:440.

7. Bio informatics: searching the net. Serm Nucl Med 1998, 28:177-187.

8. Jones RB, Navin LM, Barrie J, Hillan E and Kinane D: Computer literacy among medical, nursing, dental and veterinary undergraduates. Med Educ 1991, 25:191-195.

9. Mansor I: Computer skills among medical students: a survey at the King Abdul Aziz University, Jeddah. J Ayub Med Coll 2002, I4(3): 13-15.

10. Mattheos N, Nattestad A, Schittek M and Attstrom R: Computer literacy and attitudes among students in 16 European dental schools: current aspects, regional differences and future trends. Eur J Dent Edu 2002, 6(I):30-35.

II. Virtanen $\mathrm{Jl}$ and Nieminen P: Information and communication technology among undergraduate dental students in Finland. Eur J Dent Edu 2002, 6(I): I47-I52.

12. Odusanya $O O$ and Bamgbala $O$ : Computing and information technology skills of final year medical and dental students at the College of Medicine, University of Lagos, Nigeria. Niger Post grad Med J 2002, 9(4): 189-193.

13. Atack $L$ and Rankin J: A descriptive study of registered nurses experiences with web-based learning. J Adv Nurs 2002, 40(4):315-319.

14. Hong $\mathrm{CH}$, Mclean D, Shapiro J and Lui $\mathrm{H}$ : Using the internet to assess and teach medical students in dermatology. J Cutan Med Surg 2002, 6(4):315-319.

15. Grimes EB: Student's perceptions of an online dental terminology course. J Dent Edu 2002, 66(I): 100-107.

16. Hayward LM and Cairns MA: Allied health students' perceptions of and experiences with internet-based study instruction. $J$ Allied Health 2002, 30(4):232-238.

17. Sear AM and Douglass DB: Use of internet for real-time instruction in a graduate health services administration program. Health Adm Edu 1998, I 6(4):425-427.

18. Ward JPT, Gordon J, Field MJ and Lehmann HP: Communication and information technology in medical education. Lancet 200I, 357:792-796.

19. University College Hospital Hand Diary. 2002.

20. Nurjahan MI, Lim TA, Yeong SW, Foong AL and Ware J: Utilization of information technology in medical education: a questionnaire survey of students in a Malaysian institution. Med J Malaysia 2002, 57(suppl E):58-66.

21. Johns Hopkins Bloomberg School of Public Health Students handbook, 2002-2003. Johns Hopkins Press.

22. Walmsley AD, White DA, Eynon R and Somerfield $L$ : The use of the Internet within a dental school. Eur J Dent Edu 2003, I(I):27-33.

\section{Pre-publication history}

The pre-publication history for this paper can be accessed here:

http://www.biomedcentral.com/1472-6947/3/10/prepub
Publish with Biomed Central and every scientist can read your work free of charge

"BioMed Central will be the most significant development for disseminating the results of biomedical research in our lifetime. "

Sir Paul Nurse, Cancer Research UK

Your research papers will be:

- available free of charge to the entire biomedical community

- peer reviewed and published immediately upon acceptance

- cited in PubMed and archived on PubMed Central

- yours - you keep the copyright

Submit your manuscript here:

http://www.biomedcentral.com/info/publishing_adv.asp
BiolMedcentral 